\title{
Total above-ground biomass and biomass in commercial logs following the harvest of spotted gum (Corymbia maculata) forests of SE NSW
}

\author{
Fabiano A. Ximenes ${ }^{1,2}$, W. David Gardner ${ }^{1}$ and Gary P. Richards ${ }^{3}$ \\ ${ }^{1}$ Cooperative Research Centre for Greenhouse Accounting and Forest Resources Research, \\ NSW Department of Primary Industries, PO Box 100, Beecroft, NSW 2119, Australia \\ 2Email: fabianox@sf.nsw.gov.au \\ ${ }^{3}$ National Carbon Accounting System, Australian Greenhouse Office, GPO Box 621, Canberra, ACT 2601, Australia and \\ Visiting Fellow, School of Resources, Environment and Society, The Australian National University, ACT 0200, Australia
}

Revised manuscript received 21 November 2005

\begin{abstract}
Summary
Total stand above-ground biomass (AGB) was measured at three sites of varying productivity in the Batemans Bay region of NSW. All trees with diameter at breast height $(\mathrm{dbh})>10 \mathrm{~cm}$ on three plots of 0.4-0.6 ha were weighed. Spotted gum was the dominant tree species across all sites. The basal area ranged from 29 to $43 \mathrm{~m}^{2} \mathrm{ha}^{-1}$ depending on site quality.

The total dry AGB was 220, 287 and $397 \mathrm{t} \mathrm{ha}^{-1}$ for the low, medium and high-quality sites (LQS, MQS and HQS), respectively. Spotted gum accounted for 66-79\% of the AGB. The proportion of AGB in larger trees $(\mathrm{dbh}>50 \mathrm{~cm})$ increased significantly with increased site quality. Bark accounted for about $7 \%$ of the weight of all spotted gum logs. The only significant differences in the proportion of bark in the logs were between trees with $\mathrm{dbh}>70 \mathrm{~cm}$ and those with $\mathrm{dbh}<40 \mathrm{~cm}$. Ironbark had the highest proportion of the log biomass in the bark (12.4\%).
\end{abstract}

The mean moisture content of spotted gum logs was similar to that of Sydney blue gum and yellow stringybark logs. The moisture content of ironbark logs was significantly lower than that of all other species tested, whereas its basic density was higher than that of all other species.

A strong correlation $\left(r^{2}=0.947\right)$ was found between tree diameter and AGB for spotted gum across all sites. Most trees on all sites were $<30 \mathrm{~cm}$ in diameter (particularly at the low-quality site), and the variance of AGB increased with tree size.

The fraction of biomass in all spotted gum commercial logs was $58.2 \%$. The biomass in commercial logs at the MQS was significantly greater than that at both the LQS and the HQS. An average $0.8 \mathrm{t}$ of residues was generated per tree as a result of selective harvesting of commercial spotted gum forests.

The largest fraction of biomass in commercial spotted gum logs $(64.1 \%)$ was found in large trees $(55-65 \mathrm{~cm} \mathrm{dbh})$, although the only significant differences were between trees with dbh between 35 and $40 \mathrm{~cm}$ and those with dbh between 55 and $65 \mathrm{~cm}$. Pulp $\operatorname{logs}$ accounted for $55 \%$ of the AGB harvested in spotted gum commercial logs. The proportion of higher-quality commercial logs increased with increased site quality.
Keywords: biomass; dry matter distribution; bark; wood; wood density; moisture content; log grade; log size; native forests; models; Corymbia maculata; New South Wales

\section{Introduction}

We determined the total above-ground biomass (AGB) in three forest areas of different productivity in the Batemans Bay region (south-eastern NSW, Fig. 1) considered to be close to, or at, maximum biomass carrying capacity (i.e. there had been a long recovery period since known disturbance). The primary objective was to obtain calibration data for forest productivity models. These models are used to estimate the carbon sequestered in biomass in Australian forests. There is a distinct lack of directly weighed, reliable AGB data for Australian native forests, particularly for trees of large diameter. A second objective was to determine the proportion of AGB in commercial logs and other tree components of important commercial species.

Weighing trees in the field is the most reliable method for determining the AGB for trees of varying diameter at breast height (dbh). However, this method can present many logistical problems and it is normally considered too difficult and expensive to use. Brown (2002) pointed out that weighing trees, particularly those of large diameter, is essential in the development of accurate biomass regression models and allometric regression equations.

Knowledge of the proportion of AGB present in commercial logs after harvest is an important factor in determining the contribution of wood products to carbon storage. The proportion of AGB in commercial logs varies according to factors such as market availability (e.g. whether there is local demand for pulp logs), species, harvesting system, silvicultural systems (e.g. clear fell versus selective logging) and stand quality. Spotted gum (Corymbia maculata), the main tree species in the stands selected for the study, is an important commercial hardwood species in Australia. In NSW it is the second-most-important commercial hardwood species, with $>150000 \mathrm{~m}^{3}$ of sawlogs removed in 1999/2000 (State Forests of NSW 2000).

Data on the residues left in the forest after the harvest of commercial trees, as well as data on the different types of residues, 
are also important, since the fate of residues may vary significantly. The carbon in the harvest residues in the forest may be released at varying rates, affecting the greenhouse gas emissions due to forestry activities.

\section{Materials and methods}

\section{Field studies}

All sites were located on the southern coast of NSW, in the Batemans Bay region (Fig. 1). Their arboreal vegetation consisted of mixed, uneven-aged eucalypts, with spotted gum (until recently regarded as a eucalypt) being the dominant (both most abundant and tallest) species. The climate in the area is meso-thermal with an average annual rainfall of about $1000 \mathrm{~mm}$. Selection of suitable sites was based on local knowledge, estimates of basal area and the number of dominant trees. These parameters were also used to assess the level of prior disturbance in the study area. The areas identified were considered to be close to or at maximum biomass carrying capacity. The medium and low-quality study plots were harvested in late 2003 and the high-quality plot in early 2004. The harvesting of the trees and the determination of their weights was carried out over about one week at each site.
The precise area of each plot was determined using a Global Positioning System after the other work was completed.

\section{Productivity of sites}

Summary descriptions of the low-quality site (LQS), mediumquality site (MQS) and high-quality site (HQS) are presented in Table 1. Detailed information on each of the sites is provided in Ximenes et al. (2005b).

\section{Sequence of events}

The trees were felled and, when their size permitted, snigged intact to the logging dump by a skidder or excavator. In the case of large trees, the crown component was cut from the bole in the forest and the components were snigged separately to the logging dump. A visual assessment was made of any losses (crown, branches and bark) occurring during transport from the stump to the logging dump and during handling at the dump. The boles were assessed for their commercial status and the commercial logs were cut, weighed, debarked, graded and re-weighed. Samples were cut from the commercial logs, crown and bark for laboratory analysis (moisture content, density and sapwood content).

\section{Weighing equipment and weighing different tree components}



Figure 1. Location of the three total above-ground biomass harvest sites
Biomass was weighed on weigh bars mounted on top of a purpose-built trailer (Fig. 2). An excavator was used to lift the biomass components onto the trailer. The trailer was equipped with a heavy upper frame and each corner was supported by a two-speed drop leg. The nominal dimensions of the trailer were:

- length of load space: $2.5 \mathrm{~m}$; length overall: $4.1 \mathrm{~m}$; - width of load space: $1.8 \mathrm{~m}$; width overall: $1.8 \mathrm{~m}$.

Both weigh bars were equipped with two load cells with a combined capacity of $5 \mathrm{t}$. Weight increments of $0.2 \mathrm{~kg}$ were shown on a digital display.

The weight of stumps was determined by multiplying their volume by the green density of the butt section of the respective trees. Dead trees were also weighed. Minor components such as small palms and grassy material were not weighed. A rubbish skip was placed on top of the weighing trailer to allow the weighing of all the slash left on the site after the harvesting of all trees on the medium-quality site. The quantity of slash on the low and high-quality

Table 1. Description of the low (LQS), medium (MQS) and high (HQS) quality sites

\begin{tabular}{llccccc}
\hline Site quality & Location & $\begin{array}{c}\text { Area } \\
\text { (ha) }\end{array}$ & $\begin{array}{c}\text { Latitude } \\
(\mathrm{E})\end{array}$ & $\begin{array}{c}\text { Longitude } \\
(\mathrm{S})\end{array}$ & $\begin{array}{c}\text { Number of } \\
\text { trees }\end{array}$ & $\begin{array}{c}\text { Last sawlog } \\
\text { harvest activity }\end{array}$ \\
\hline Low & Mogo SF & 0.51 & $35^{\circ} 44^{\prime}$ & $150^{\circ} 04^{\prime}$ & 209 & 1976 \\
Medium & Clyde SF & 0.63 & $35^{\circ} 27^{\prime}$ & $150^{\circ} 12^{\prime}$ & 156 & 1981 \\
High & Flat Rock SF & 0.45 & $35^{\circ} 25^{\prime}$ & $150^{\circ} 18^{\prime}$ & 162 & 1979 \\
\hline
\end{tabular}




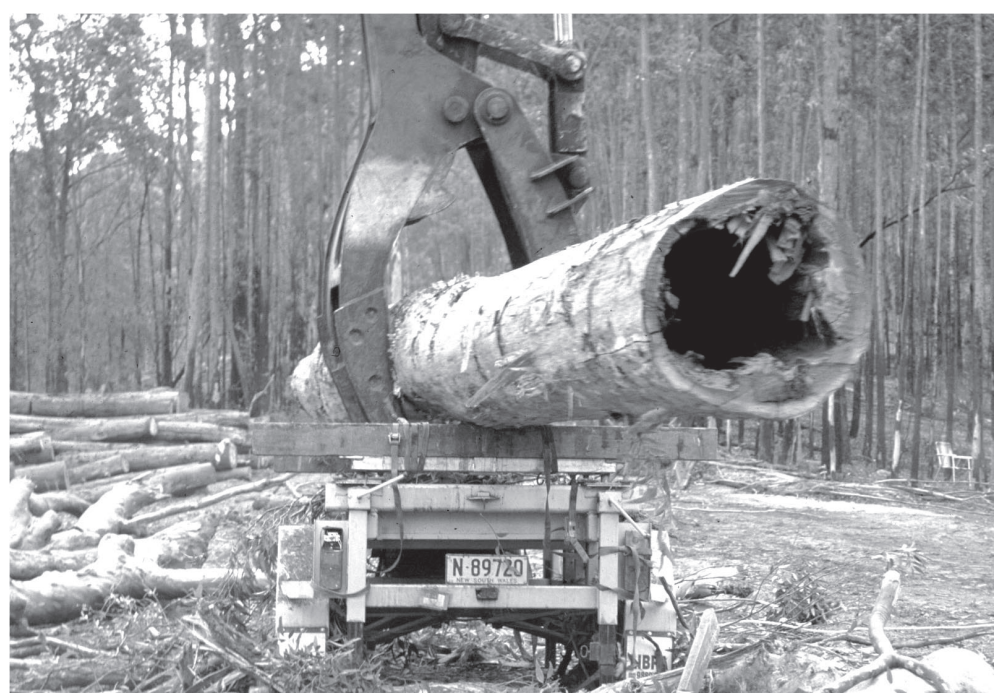

Figure 2. Weighing trailer

sites was estimated visually. The estimated weight of biomass lost during transport and handling of the trees was discounted from the estimated total biomass of the slash left on each of the sites.

\section{Grading of commercial logs}

The commercial logs were graded as sawlog (quota or salvage), pulp or firewood. Quota logs are high-quality sawlogs (middiameter $>40 \mathrm{~cm}$ ), whereas salvage logs are sawlogs of lower quality with a greater amount of defect.

\section{Proportion of bark in the logs}

The weight and proportion of bark in the commercial logs was determined for a total of 122 spotted gum, 16 yellow stringybark (Eucalyptus muellerana), 16 Sydney blue gum (E. saligna) and eight ironbark (E. paniculata) trees. The logs from those trees were weighed, debarked and reweighed to provide the weight of bark. The analysis included at least the butt log, but when the data were available it also included any other additional log product that the same tree may have yielded. The proportion of bark was calculated from the dry weights of the logs and the bark.

\section{Sampling of logs, bark and crown}

Discs about $50 \mathrm{~mm}$ thick were cut from the butt and top of 110 logs after debarking (39, 41 and 30 from the LQS, MQS and HQS respectively). Random samples (46, 26 and 18 samples from 32, 15 and 15 trees at the LQS, MQS and HQS respectively) were taken of bark and branches in the crowns of the sampled trees. All samples were placed separately in plastic bags and sealed to avoid moisture loss.

\section{Density}

Samples ('V'-shaped wedges) cut from discs were used to determine the density of randomly-selected logs. The wedges varied in size as the size of the discs varied from tree to tree the combined wedges covered at least $10 \%$ of the area of the disc. There were two wedges per disc. The samples were weighed and placed in an oven at $103 \pm 2{ }^{\circ} \mathrm{C}$ (ASTM D2395-93 1993). The oven-dry samples were cooled in a desiccator prior to weighing and their volume was determined by the water displacement method (ASTM D2395-93 1993). The density of the samples was calculated as the average of four measurements and expressed as:

green density $\left(\mathrm{kg} \mathrm{m}^{-3}\right)=1000 \times \frac{\text { green weight }(\mathrm{g})}{\text { green volume }\left(\mathrm{cm}^{3}\right)}$,

and

basic density $\left(\mathrm{kg} \mathrm{m}^{-3}\right)=1000 \times \frac{\text { oven-dry weight }(\mathrm{g})}{\text { green volume }\left(\mathrm{cm}^{3}\right)}$.

\section{Moisture content}

Samples used for the determination of wood density were also used for the determination of moisture content. The moisture content of the samples was determined by oven drying in accordance with AS/NZ 1080.1 (1997). The results were calculated on both an oven-dry and a green basis according to the following formulae:

moisture content on a green basis $(\%)$

$$
=100 \times \frac{\text { green weight }(\mathrm{g})-\text { oven-dry weight }(\mathrm{g})}{\text { green weight }(\mathrm{g})},
$$

and

moisture content on an oven-dry basis (\%)

$$
=100 \times \frac{\text { green weight }(\mathrm{g})-\text { oven-dry weight }(\mathrm{g})}{\text { oven-dry weight }(\mathrm{g})} .
$$

The moisture content of each log was calculated as the average of four measurements (two samples per disc). The moisture content of the stumps was calculated using the moisture content determined for the butt discs only of the corresponding logs. The dry weights of all tree components were calculated by multiplying their fresh weights by the moisture contents (green basis) of the relevant components.

\section{Sapwood and heartwood content}

The sapwood content of each disc was determined according to AS/NZS 1605 : 2000 (2000). Samples where the boundary between sapwood and heartwood was not easily identified were spot-tested with a $0.1 \%$ solution of methyl orange. The assessment was carried out on the discs at four points across their diameter. An average sapwood content figure was obtained for each disc. The following formula was used to calculate the percentage of sapwood in each disc:

sapwood content (\%)

$$
=100 \times \frac{\text { disc area }\left(\mathrm{cm}^{2}\right)-\text { heartwood area }\left(\mathrm{cm}^{2}\right)}{\text { disc area }\left(\mathrm{cm}^{2}\right)} .
$$




\section{Statistical analysis}

\section{Proportion of bark in logs}

The measured proportions of bark in logs were arcsine square root transformed to adjust for unequal variances of responses (Sokal and Rohlf 1995). An analysis of variance (ANOVA) was carried out on the transformed data, followed by Tukey HSD post hoc tests for pair-wise comparisons between treatments.

\section{Biomass in commercial logs}

As the biomass in commercial logs showed differing variability in different dbh classes, weighted least squares (WLS) analysis was used. (The weights used were the reciprocals of the sample variances from the set of replicate measurements to which the data point belonged.) This was followed by Tukey HSD tests between treatments.

\section{Relationship between AGB and dbh}

The relationship between AGB and dbh was modelled using multiple regressions. A weighted least squares method was used to minimise the heteroscedasticity of the trees, as the variance increased with increased dbh values. Site quality and species were introduced as dummy variables to test the significance of these effects. Data for spotted gum trees from all sites were combined. The relationship between AGB and dbh of spotted gum trees was fitted using the following equation:

$$
\mathrm{AGB}=b_{0}+b_{1}(\mathrm{dbh})+b_{2}(\mathrm{dbh})^{2}+b_{3}(m q s)+b_{4}(h q s),
$$

where $b_{i}(i=0, \ldots, 4)$ are the regression coefficients and $m q s=1$ if site is MQS ( 0 otherwise) and $h q s=1$ if site is HQS ( 0 otherwise).

The significance of the species effects was tested by combining AGB data for spotted gum, Sydney blue gum, ironbark and yellow stringybark. The number of trees for the remaining species was too low to give meaningful results. The regression equation fitted to these data was the same as the 'AGB' equation above, with the inclusion of dummy variables for species effect.

The statistical analyses were carried out using S-PLUS ${ }^{\circledR}$ version 7.0 and Statistica version 7.0.

\section{Results and discussion}

\section{Diameter at breast height and stand basal areas}

A summary of the dbh of the two main species at each site is given in Figure 3.

Spotted gum was the dominant tree species at all sites, followed by ironbark at the LQS, yellow stringybark at the MQS and Sydney blue gum at the HQS. Other species included red mahogany (Eucalyptus pellita) at the MQS, white stringybark (E. globoidia) at the LQS and HQS and wattles (Acacia spp.) at the HQS. The mean dbh of spotted gum at the LQS was much lower than that at either the MQS or HQS (Fig. 3). The mean dbh of trees at the MQS was higher than that at the HQS. This was mostly due to the fact that the HQS had a high proportion of wattle and dead trees (stand basal area of 0.8 and $0.86 \mathrm{~m}^{2} \mathrm{ha}^{-1}$ respectively). The basal area for the low, medium and high-quality sites was 29.3, 33.6 and $42.9 \mathrm{~m}^{2} \mathrm{ha}^{-1}$ respectively. As expected, the stand basal area increased with increased site quality, reflecting the size of the trees and the density of the forest. Most estimates of basal area for mature uneven-aged eucalypt forests range from 20 to $60 \mathrm{~m}^{2} \mathrm{ha}^{-1}$ (Hillis and Brown 1978).

\section{Tree height}

A summary of the tree heights of the two main species at each site is given in Figure 4.

The average height of trees increased with increased site quality (Fig. 4). The tallest trees were found at the HQS. The tallest tree across all sites was a Sydney blue gum at the HQS (48.5 m).

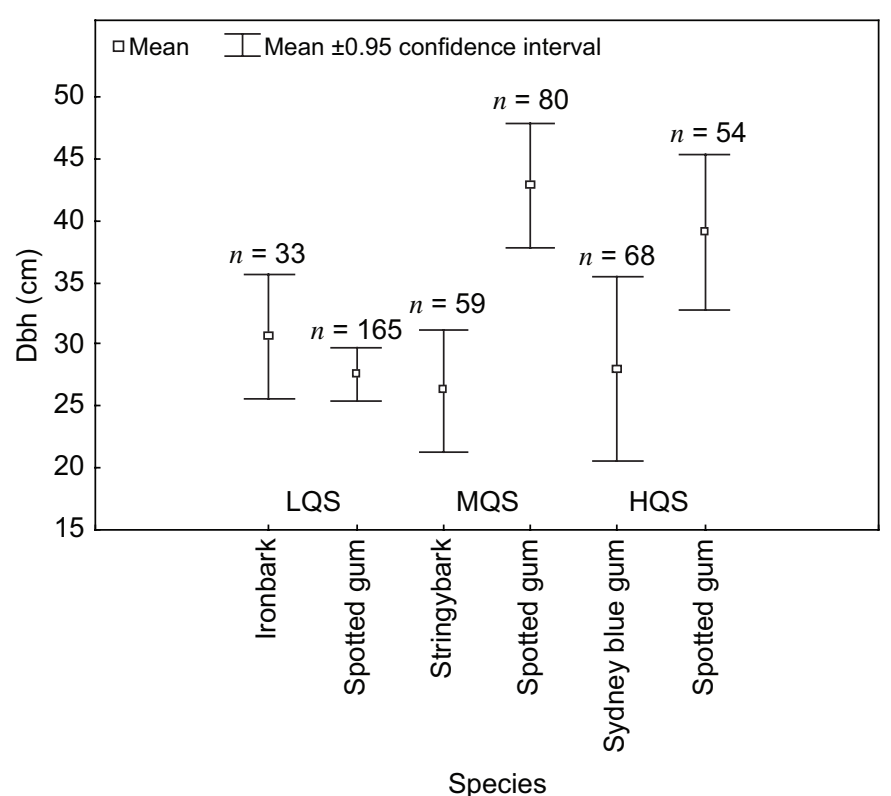

Figure 3. Mean dbh of the main species in the study sites

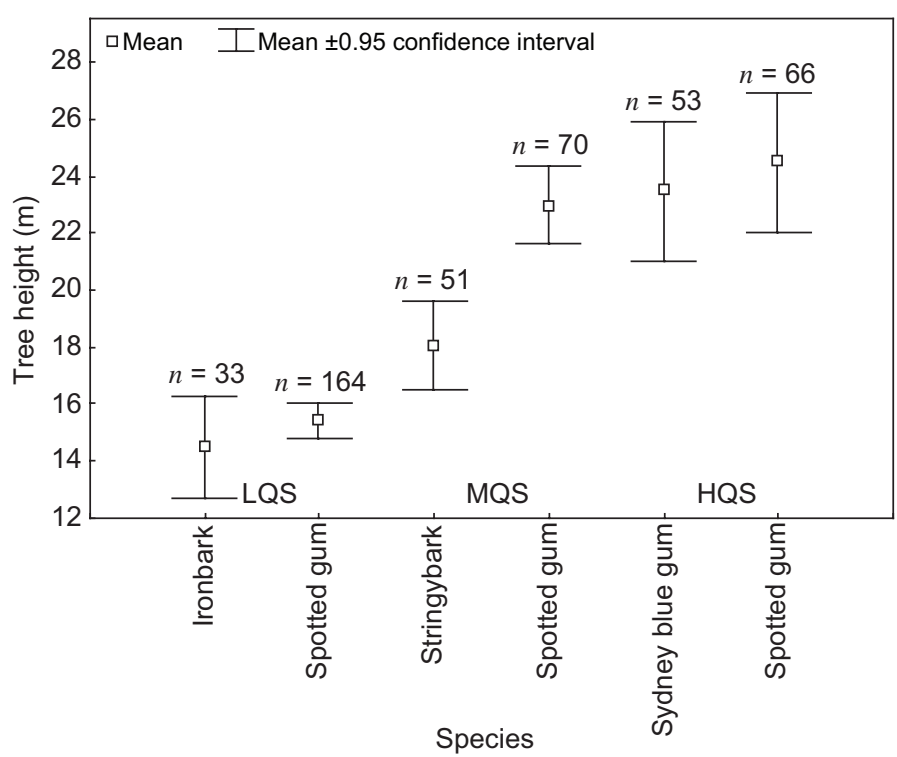

Figure 4. Mean height of the main species in the study sites. The tips of some trees were lost in felling, so there are fewer trees in this figure than in Figure 3. 
Spotted gums had the greatest mean height $(24.5 \mathrm{~m})$ among all species across all sites.

\section{Total dry above-ground biomass}

The total dry AGB at each site is given in Table 2. The amount of slash left at each site and included in the totals was 12.6, 26.2 and $8.0 \mathrm{t} \mathrm{ha}^{-1}$ of dry biomass for the LQS, MQS and HQS respectively.

As expected, the HQS had the highest dry AGB of all sites, with about $400 \mathrm{t} \mathrm{ha}^{-1}$ (Table 2). The dry AGB at the HQS was $38 \%$ greater than that at the MQS, which in turn was $30 \%$ greater than that at the LQS. A wide range of estimates of AGB in mature native forests in Australia can be found in Keith et al. (2000) and Raison et al. (2003). The estimates typically range from $<100 \mathrm{t} \mathrm{ha}^{-1}$ to, in some cases, almost $900 \mathrm{t} \mathrm{ha}^{-1}$ for different communities and environmental conditions. Most of these estimates are derived from allometric and volume equations rather than direct weighing.

A summary of the total dry AGB of each tree species at each site is given in Table 3. Spotted gum accounted for $66-79 \%$ of the AGB. As the site quality increased, the proportion of the AGB in spotted gum decreased (Table 3). Ironbark, yellow stringybark and Sydney blue gum accounted for the second highest proportion of AGB at the LQS, MQS and HQS respectively. Dead trees accounted for only $0.2-0.6 \%$ of the AGB. Feller (1980) estimated that dead trees represented 3-5\% of the live AGB in a 38-y-old mountain ash (E. regnans) and messmate stringybark (E. obliqua)

Table 2. Above-ground biomass in all study sites

\begin{tabular}{lc}
\hline Site quality & AGB $\left(\mathrm{t} \mathrm{ha}^{-1}\right)$ \\
\hline High (HQS) & 397.3 \\
Medium (MQS) & 287.0 \\
Low (LQS) & 220.2 \\
\hline
\end{tabular}

Table 3. Summary of the above-ground biomass, excluding slash, in all study sites

\begin{tabular}{lrrr}
\hline Site and tree species & $\begin{array}{c}\text { Number of trees } \\
(n)\end{array}$ & $\begin{array}{c}\text { Total AGB } \\
\left(\mathrm{t} \mathrm{ha}^{-1}\right)\end{array}$ & $\begin{array}{r}\text { Fraction of total AGB } \\
(\%)\end{array}$ \\
\hline Low-quality site — Mogo SF & & & \\
$\quad$ Spotted gum & 164 & 164.7 & 79.4 \\
$\quad$ Ironbark & 33 & 37.2 & 18.0 \\
$\quad$ White stringybark & 8 & 5.0 & 2.4 \\
$\quad$ Dead & 2 & 0.4 & 0.2 \\
Total & 207 & 207.3 & \\
Medium-quality site — Clyde SF & & & \\
Spotted gum & 80 & 196.7 & 75.4 \\
$\quad$ Yellow stringybark & 59 & 58.3 & 22.3 \\
Others & 13 & 4.9 & 1.8 \\
Dead & 4 & 0.9 & 0.4 \\
Total & 156 & 260.8 & \\
High-quality site - Flat Rock SF & & & 66.5 \\
Spotted gum & 68 & 258.9 & 29.6 \\
Sydney blue gum & 54 & 115.1 & 3.3 \\
Others & 26 & 12.6 & 0.6 \\
Dead & 14 & 2.4 & \\
Total & 162 & 389.3 & \\
\hline
\end{tabular}

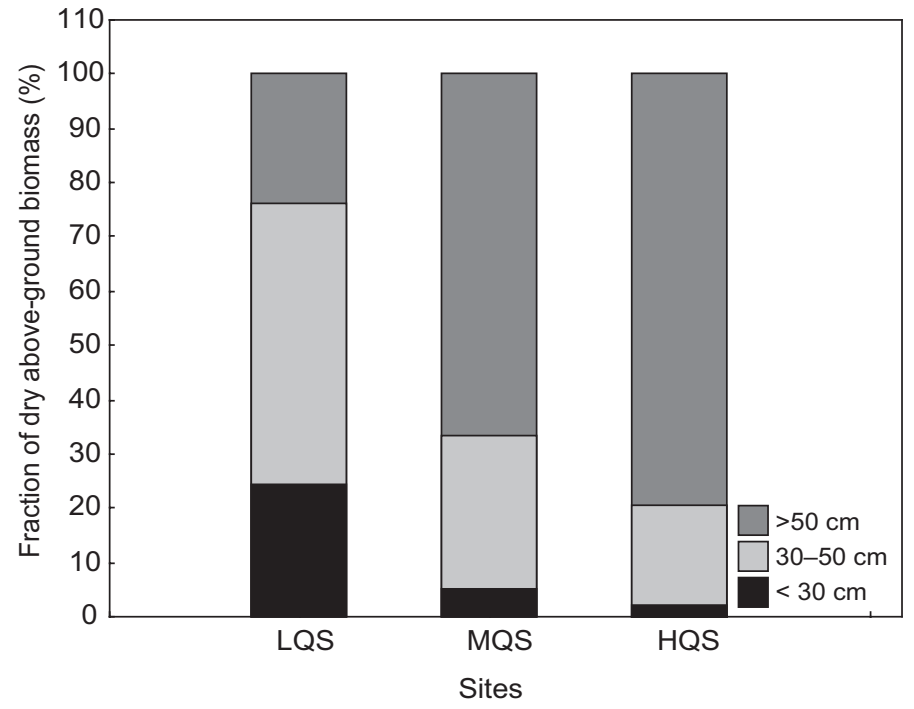

Figure 5. Fraction of the dry above-ground biomass contained in spotted gum trees of three dbh classes across the study sites

Table 4. Proportion of bark (by weight) in commercial logs from the main commercial species at the study sites

\begin{tabular}{lccc}
\hline Species & $\begin{array}{c}\text { Number } \\
\text { of logs }\end{array}$ & $\begin{array}{c}\text { Proportion } \\
\text { of bark }(\%)\end{array}$ & $\begin{array}{c}\text { Standard } \\
\text { deviation }\end{array}$ \\
\hline Spotted gum & 122 & 6.8 & 1.8 \\
Yellow stringybark & 16 & 8.7 & 3.0 \\
Sydney blue gum & 16 & 7.7 & 2.3 \\
Ironbark & 8 & 12.4 & 1.9 \\
\hline
\end{tabular}

stand. The heaviest tree in our plots was a Sydney blue gum at the HQS, which weighed $16.3 \mathrm{t}$ (dry weight).

Figure 5 shows the contribution of three dbh classes of spotted gum to the total AGB. This indicates that the higher the productivity of the site, the greater proportion of the biomass will be contained in the higher dbh classes.

\section{Proportion of bark in the logs}

Table 4 shows the contribution of bark to log dry weight for commercial trees of four species over all sites. Bark ranged, on average, from $6.8 \%$ of the weight of spotted gum logs to $12.4 \%$ of the weight of ironbark logs. It is important to determine the proportion of bark for different species, particularly since hardwood logs are normally debarked in the forest. The bark of trees is in many respects very different from the woody component (e.g. in anatomy, moisture content, nutrient content and density) and when left in the forest it may decay at a rate different from that of woody debris. 
A more detailed analysis on the proportion of bark on spotted gum logs and its relationship with dbh is presented in Table 5. The bark proportion generally decreased with increased dbh of trees (Table 5). The ANOVA showed there were significant differences $(P<0.05)$ in the proportion of bark in the logs of trees with $\mathrm{dbh}>70 \mathrm{~cm}$ and those with dbh $<30 \mathrm{~cm}$ and with dbh $30-40 \mathrm{~cm}$ ( $P=0.00027$ and $P=0.036$, respectively). The decrease in the proportion of bark in logs of trees with higher dbh contributes to a higher AGB in commercial logs obtained from larger trees following harvest.

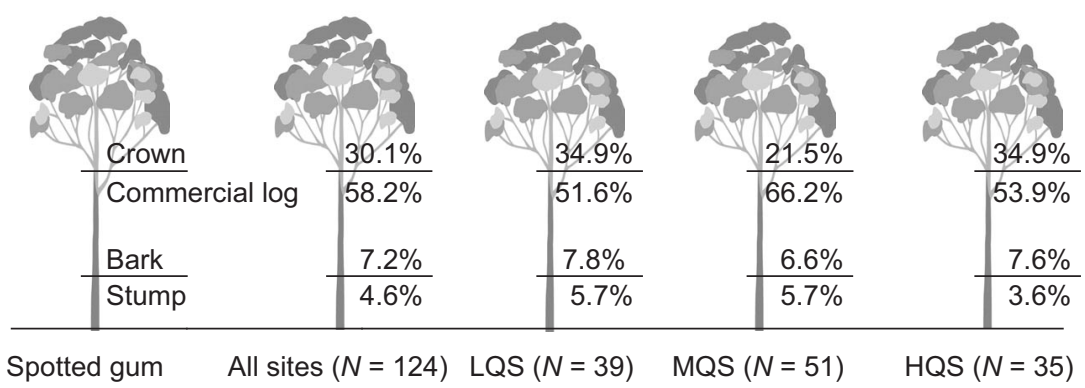

Figure 6. Fraction of the above-ground biomass allocated to tree components in the commercial spotted gum trees

\section{Biomass in commercial logs and residues}

The biomass in commercial logs and residues for commercial spotted gum trees is shown in Figure 6. The biomass in commercial logs at the MQS was significantly greater than at both the LQS and HQS. The biomass in commercial logs for all spotted gum trees was $58.2 \%$ of total AGB. The remaining biomass (41.8\%) was left in the forest after harvesting as residue. Given that the average dry weight of each commercial spotted gum tree from all sites was $1.94 \mathrm{t}$, the average amount of residue left per tree after the spotted gum harvesting operation was $0.8 \mathrm{t}$. There are only a few references in the literature to the fraction of biomass held in commercial logs after harvesting operations. Stewart et al. (1979) assumed that 33\% of biomass would be present in commercial logs after selective logging of native hardwood forests. Snowdon et al. (2000) suggested that when pulpwood is utilised in the harvesting of native forests, the proportion of merchantable AGB may vary between 50 and $77 \%$. In previous hardwood harvesting studies the fraction of AGB in commercial logs (based on weight of carbon) ranged from $45 \%$ for blackbutt (Eucalyptus pilularis) (Ximenes et al. 2005a) to $70 \%$ for messmate stringybark (Ximenes and Gardner, unpublished data).

Since it was not possible to obtain debarked weights for the crown component, the proportion of bark from the main stem was applied to the crown component and used to calculate the total weight of bark in the tree. The bark component represented on average $7.2 \%$ of the total weight of commercial spotted gum trees and did not change significantly with change in site productivity (Fig. 6). The calculated stump weight of commercial spotted gum trees accounted for $4.6 \%$ of the AGB.

Table 5. Proportion of bark (by weight) in logs from spotted gum trees of varying dbh across all study sites. Two trees lost most of their bark in snigging and could not be included in this assessment.

\begin{tabular}{lccc}
\hline $\begin{array}{l}\text { Dbh range } \\
(\mathrm{cm})\end{array}$ & $\begin{array}{c}\text { Number } \\
\text { of trees }\end{array}$ & $\begin{array}{c}\text { Mean bark } \\
(\%)\end{array}$ & $\begin{array}{c}\text { Standard } \\
\text { deviation }\end{array}$ \\
\hline$<30$ & 15 & 7.7 & 2.0 \\
$30-40$ & 31 & 7.2 & 1.9 \\
$40-50$ & 34 & 6.9 & 1.7 \\
$50-60$ & 19 & 6.4 & 1.6 \\
$60-70$ & 10 & 6.2 & 1.5 \\
$>70$ & 13 & 5.4 & 1.4 \\
\hline Total & 122 & 6.8 & 1.8 \\
\hline
\end{tabular}

Table 6. Summary of moisture contents, densities and sapwood content of discs from spotted gum logs (71 trees)

\begin{tabular}{lccc}
\hline Properties & Mean & SD & Range \\
\hline Moisture content $(\%)^{1}$ & 38.6 & 3.7 & $29-50$ \\
Moisture content $(\%)^{2}$ & 63.5 & 10 & $25-101$ \\
Basic density $\left(\mathrm{kg} \mathrm{m}^{-3}\right)$ & 715 & 56 & $513-884$ \\
Green density $\left(\mathrm{kg} \mathrm{m}^{-3}\right)$ & 1165 & 59 & $954-1263$ \\
Sapwood content $(\%)$ & 26.6 & 10.2 & $4-60$ \\
\hline
\end{tabular}

${ }^{1}$ Wet basis; ${ }^{2}$ Dry basis

\section{Moisture content, densities and sapwood content of trees harvested at all study sites}

In Table 6, the moisture content, density and sapwood content data gathered for 71 spotted gum trees sampled from the three sites were combined, as the parameters assessed did not vary appreciably across site qualities (Ximenes et al. 2005b).

The moisture content of spotted gum logs (38.6\%) was similar to that of blackbutt logs from the north coast of NSW (Ximenes et al. 2005a), but significantly less than that of messmate stringybark in Tasmania (48\%, Ximenes and Gardner unpublished data). Although the green densities (average $1165 \mathrm{~kg} \mathrm{~m}^{-3}$ ) are consistent with previously-published figures for spotted gum (Bootle 1983), the basic densities (average $715 \mathrm{~kg} \mathrm{~m}^{-3}$ ) are somewhat less (740, 790 and $821 \mathrm{~kg} \mathrm{~m}^{-3}$ in Bootle 1983, Kingston and Risdon 1961 and Bolza and Kloot 1963 respectively). The mean sapwood content of the spotted gum trees was $26.6 \%$.

The moisture content, density and sapwood content of ironbark, yellow stringybark and Sydney blue gum are presented in Table 7. The main differences are in the mean moisture content, which was much lower for ironbark than for the other species, and in the basic density, which was significantly higher for ironbark (Table 7).

The densities reported in Table 7 are consistent with previouslypublished figures for the corresponding species (Bootle 1983; Kingston and Risdon 1961; Bolza and Kloot 1963). The moisture contents of the main tree components reported in Ximenes et al. (2005b) were used in the calculation of the dry AGB of the trees. 
Table 7. Summary of moisture contents, densities and sapwood content of discs from ironbark, yellow stringybark and Sydney blue gum trees in the study sites

\begin{tabular}{|c|c|c|c|c|c|c|c|c|c|}
\hline \multirow{2}{*}{ Properties } & \multicolumn{3}{|c|}{$\begin{array}{l}\text { Ironbark } \\
\text { (5 trees) }\end{array}$} & \multicolumn{3}{|c|}{$\begin{array}{l}\text { Yellow stringybark } \\
\text { (12 trees) }\end{array}$} & \multicolumn{3}{|c|}{$\begin{array}{l}\text { Sydney blue gum } \\
\text { (13 trees) }\end{array}$} \\
\hline & Mean & SD & Range & Mean & $\mathrm{SD}$ & Range & Mean & $\mathrm{SD}$ & Range \\
\hline Moisture content $(\%)^{1}$ & 27.1 & 1.7 & $25-30$ & 39.5 & 3.2 & $33-46$ & 41.1 & 3.4 & $35-50$ \\
\hline Moisture content $(\%)^{2}$ & 37.3 & 3.2 & $34-44$ & 65.7 & 8.7 & $48-86$ & 70.4 & 10 & $54-98$ \\
\hline Basic density $\left(\mathrm{kg} \mathrm{m}^{-3}\right)$ & 903 & 70 & $840-1152$ & 711 & 48 & $620-776$ & 652 & 51 & $533-778$ \\
\hline Green density $\left(\mathrm{kg} \mathrm{m}^{-3}\right)$ & 1240 & 104 & $1160-1627$ & 1177 & 49 & $1057-1239$ & 1108 & 57.5 & $959-1215$ \\
\hline Sapwood content $(\%)$ & 13 & 5.6 & $10-25$ & 14.1 & 5.4 & $5-25$ & 19.6 & 9.2 & $5-40$ \\
\hline
\end{tabular}

${ }^{1}$ Wet basis; ${ }^{2}$ Dry basis

Table 8. Summary of the weighted regression fitting of AGB for the combined spotted gum data

\begin{tabular}{lrcrl}
\hline Variables & Value & Std Error & $t$ value & $\operatorname{Pr}(>|t|)$ \\
\hline (Intercept) & 57.59 & 14.46 & 3.98 & $0.000^{*}$ \\
Dbh $(\mathrm{cm})$ & -11.99 & 1.38 & -8.69 & $0.000^{*}$ \\
Dbh $^{2}$ & 0.92 & 0.03 & 32.23 & $0.000^{*}$ \\
MQS vs. LQS & -0.71 & 7.81 & -0.09 & $0.928^{\text {ns }}$ \\
HQS vs. LQS & 3.80 & 4.78 & 0.80 & $0.427^{\text {ns }}$ \\
\hline
\end{tabular}

$*$ Significant at $<1 \% ; \mathrm{ns}=$ Non-significant

\section{Relationship between AGB and dbh}

Figures 7-12 show scatterplots of AGB versus dbh by site quality for the main species. Spotted gum was the dominant species at all sites. Most of the trees at all sites were $<30 \mathrm{~cm}$ in diameter (particularly at the LQS), and the variance of AGB increased with tree size. The AGB of dead trees was, as expected, lower than that of live trees at all sites (Figs 7-12). Interestingly, most trees with dbh $20-30 \mathrm{~cm}$ at the HQS were Sydney blue gums (Fig. 11). Wattle trees were restricted to lower dbh classes (Fig. 11).

AGB data were plotted against dbh for spotted gum trees from all sites (Figs 13 and 14).

The AGB of trees can be predicted using allometric equations based on the dbh of trees. A relationship was established using the dbh and the weighed AGB for spotted gum across all sites, and a summary of the regression parameters is included in Table 8 . There was a strong correlation between dbh and AGB for spotted gum trees across all sites $\left(r^{2}=0.947\right)$. Site effect was not significant $(P=0.706)$, validating the composite model used (Table 8). The final model was:

$$
\mathrm{AGB}=57.6-12(\mathrm{dbh})+0.92(\mathrm{dbh})^{2} .
$$

Since the species effects for spotted gum, Sydney blue gum, ironbark and yellow stringybark were highly significant after their AGB was combined $(P=0.004)$, the data for all species were not combined in one single predictive model.

\section{Biomass in commercial logs for commercial spotted gum}

Figure 15 summarises the biomass in commercial logs from spotted gum trees for a series of dbh classes. The values generally increased with increasing tree size for trees with dbh up to $65 \mathrm{~cm}$. The ANOVA showed there were significant differences between dbh classes $(P<0.05)$ for trees with dbh $35-40 \mathrm{~cm}$ and those with dbh $55-65 \mathrm{~cm}$. The trees in those dbh classes had the biggest differences in the mean biomass in commercial logs (about 49 and 64\%, respectively, Fig. 15).

\section{Commercial logs}

Pulp logs accounted for $55 \%$ of the total biomass in commercial logs from spotted gum trees from all sites (Fig. 16(a)). The proportion of sawlogs (quota and salvage logs) in commercial trees increased with an increase in site quality - from $13 \%$ at the LQS to $35 \%$ at the MQS and $48 \%$ at the HQS (Fig. 16(b),(c),(d)). 'Other' logs included commercial logs used to produce firewood and round posts.

\section{Conclusions}

The initial assessment of the quality of the sites was confirmed by the results obtained; that is, there was an increase in the total AGB with an increase in putative site quality. The proportion of biomass in commercial spotted gum logs was within the range reported previously for other hardwoods. The increase in site quality was accompanied by a higher proportion of high-quality commercial logs being obtained from those sites.

The methods developed and applied in this study enabled reliable quantification of the AGB for a total of 527 native hardwood trees across three sites of varying productivity. The methods can be applied to any type of forest for which biomass data are required, and specifically in the calibration of models that are used to predict AGB (and from this, carbon) sequestered in 




Figure 7. Above-ground biomass of trees with dbh $0-30 \mathrm{~cm}$ at the LQS



Figure 8. Above-ground biomass of trees with $\mathrm{dbh}>30 \mathrm{~cm}$ at the LQS

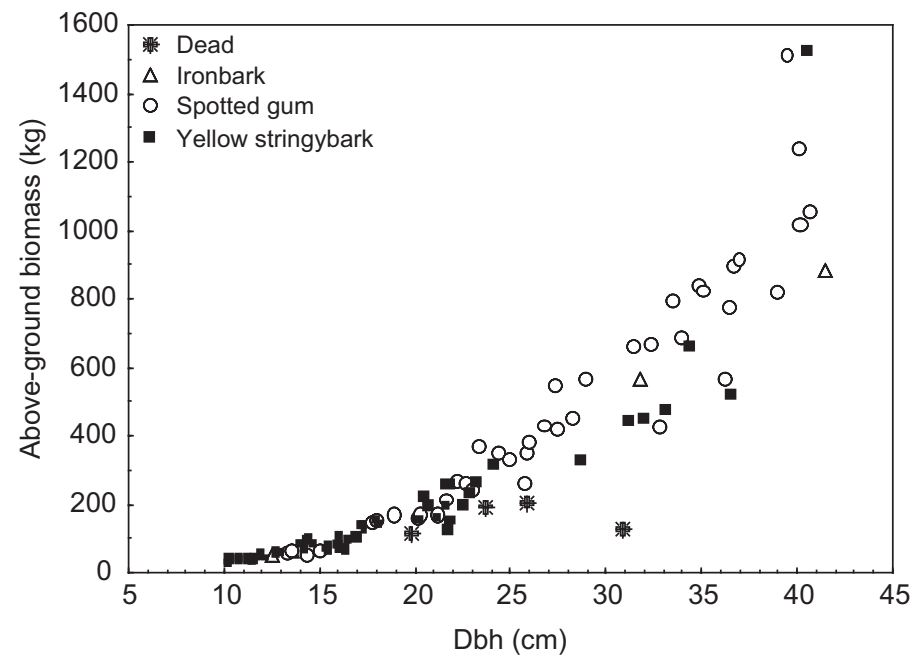

Figure 9. Above-ground biomass of trees with dbh $0-40 \mathrm{~cm}$ at the MQS

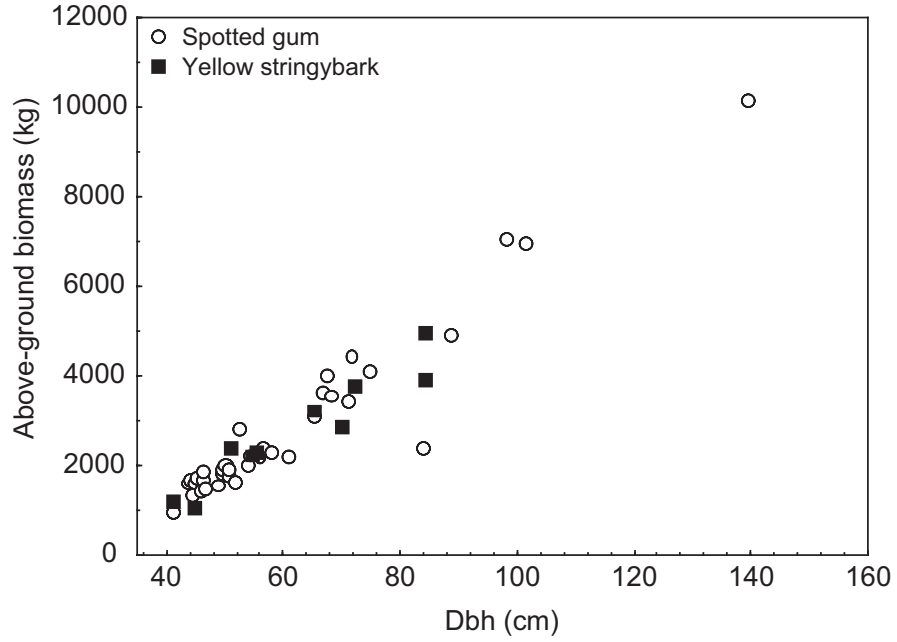

Figure 10. Above-ground biomass of trees with $\mathrm{dbh}>40 \mathrm{~cm}$ at the MQS

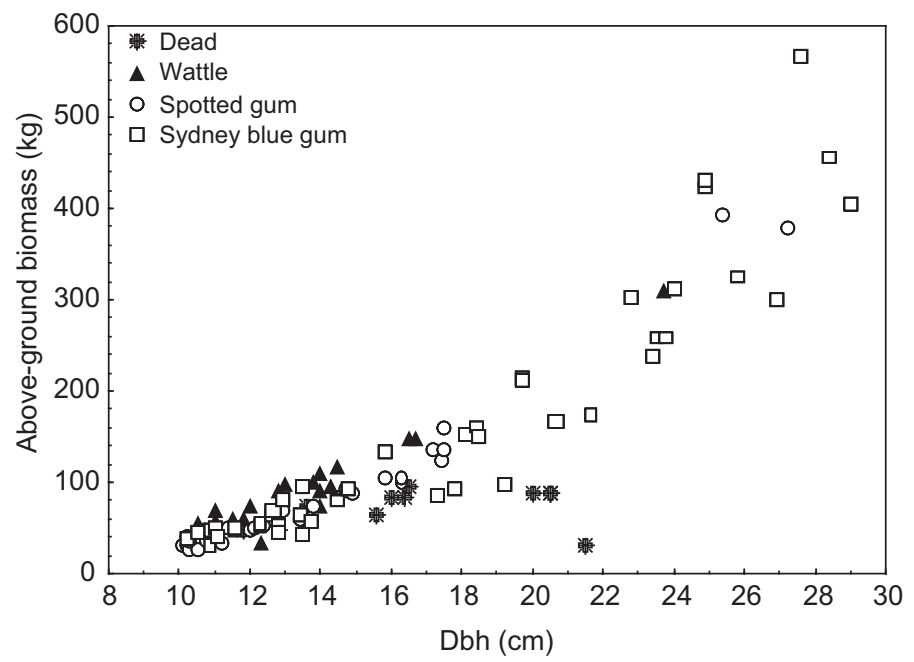

Figure 11. Above-ground biomass of trees with dbh 0-30 cm at the HQS

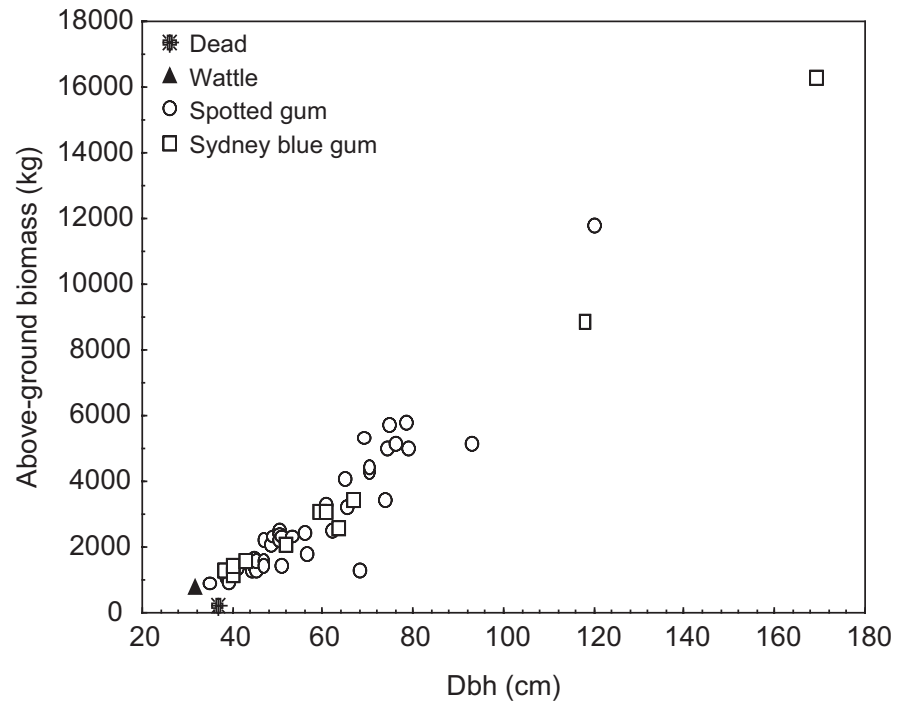

Figure 12. Above-ground biomass of trees with $\mathrm{dbh}>30 \mathrm{~cm}$ at the HQS 


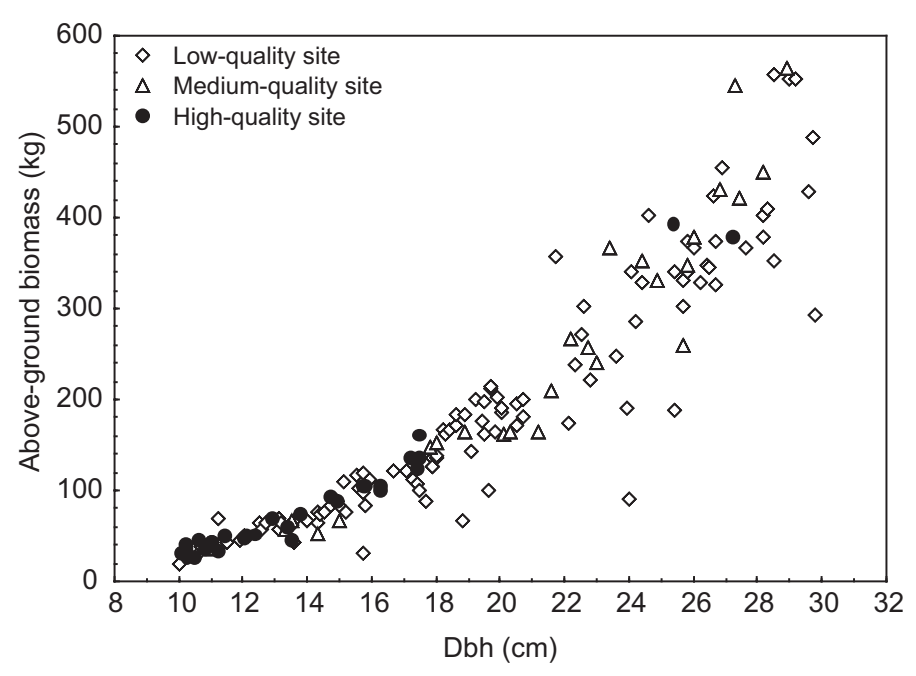

Figure 13. Above-ground biomass of spotted gum trees from all sites with dbh $0-30 \mathrm{~cm}$



Figure 14. Above-ground biomass of spotted gum trees from all sites with $\mathrm{dbh}>30 \mathrm{~cm}$

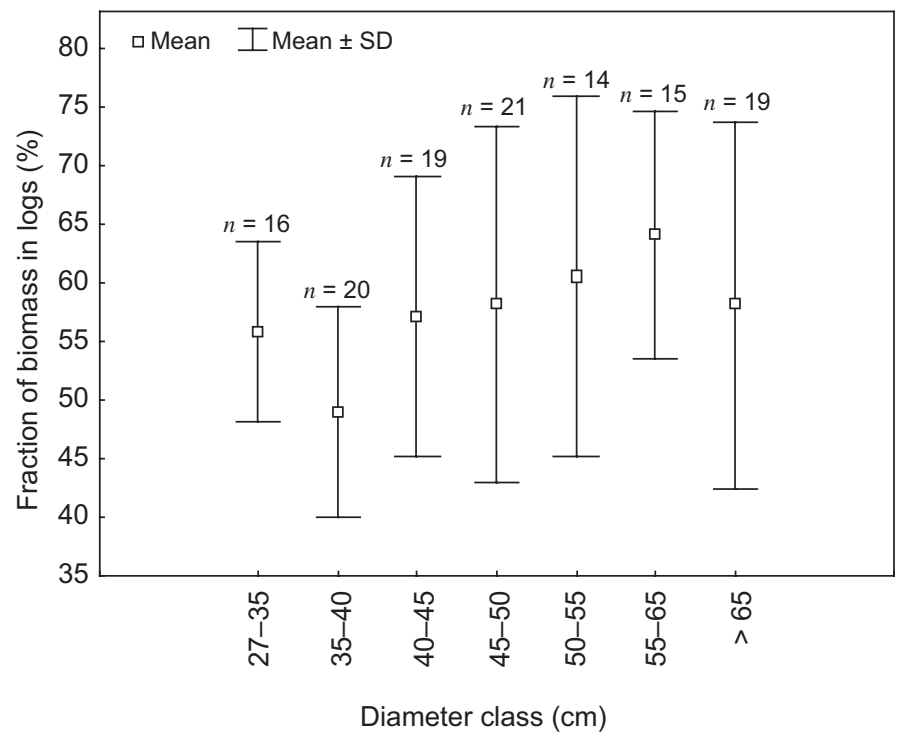

Figure 15. Fraction of biomass in commercial spotted gum logs of various dbh classes (a)

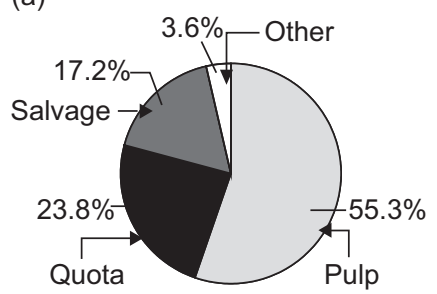

(b)



(c)

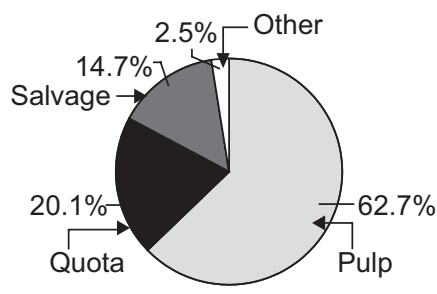

(d)

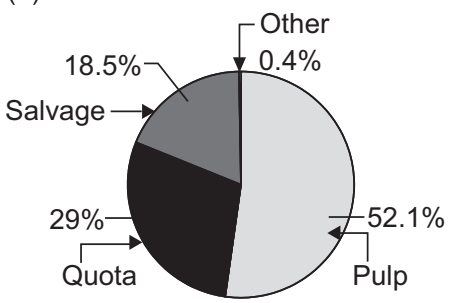

Figure 16. Proportion of commercial logs obtained after harvesting of spotted gum trees from (a) all sites, (b) the LQS, (c) the MQS and (b) the HQS

Australian forests and that are based on relationships to site productivity. The study also yielded an allometric relationship between dbh and AGB for spotted gum trees from all sites. Biomass relationships are important in carbon accounting projects in the quantification of carbon stored in trees.

\section{Acknowledgements}

We would like to acknowledge the excellent assistance provided by personnel from Forests NSW South Coast Region throughout all stages of this research project, particularly Ian Barnes, Ken Boer and David de Jong. We gratefully acknowledge the assistance provided by Forests NSW Forest Engineering Services personnel in the measurement of the plot areas, by Dr John Raison on the selection of the sites and by Dr Amrit Kathuria on the statistical analyses. Financial support was provided by the Australian Greenhouse Office and the CRC for Greenhouse Accounting. We thank the referees for their helpful comments on the manuscript.

\section{References}

ASTM D2395-93 (1993) Standard Test Methods for Specific Gravity of Wood and Wood-Based Materials. American Society for Testing and Materials International.

AS/NZS 1605:2000 (2000) Methods for Sampling and Analysing Timber Preservatives and Preservative-Treated Timber. Standards Association of Australia, Strathfield NSW, 80 pp.

AS/NZ 1080.1 (1997) Timber - Methods of Test; Method 1: Moisture Content. Standards Association of Australia, Homebush NSW, $40 \mathrm{pp}$.

Bolza, E. and Kloot, N.H. (1963) The Mechanical Properties of 174 Australian Timbers. Commonwealth Scientific and Industrial Research Organization (CSIRO) Division of Forest Products Technological Paper No. 25. 
Bootle, K.R. (1983) Wood in Australia - Types, Properties and Uses. McGraw-Hill Book Company, Sydney.

Brown, S. (2002) Measuring carbon in forests: current status and future challenges. Environmental Pollution 116, 363-372.

Feller, M.C. (1980) Biomass and nutrient distribution in two eucalypt forest ecosystems. Australian Journal of Ecology 5, 309-333.

Hillis, W.E. and Brown, A.G. (1978) Eucalypts for Wood Production. Commonwealth Scientific and Industrial Research Organization, Australia.

Keith, H., Barrett, D. and Keenan, R. (2000) Review of Allometric Relationships for Estimating Woody Biomass for New South Wales, the Australian Capital Territory, Victoria, Tasmania and South Australia. National Carbon Accounting System, Technical Report No. 5b, Australian Greenhouse Office, Canberra.

Kingston, R.S.T. and Risdon, C.J.E. (1961) Shrinkage and Density of Australian and other South-west Pacific Woods. Technological Paper No. 13, Division of Forest Products, Commonwealth Scientific and Industrial Research Organization (CSIRO).

Raison, J., Keith, H., Barrett, D., Burrows, B. and Grierson, P. (2003) Spatial Estimates of Biomass in 'Mature' Native Vegetation. National Carbon Accounting System, Technical Report No. 44, Australian Greenhouse Office, Canberra.

Snowdon, P., Eamus, D., Gibbons, P., Khanna, P., Keith, H., Raison, J. and Kirschbaum, M. (2000) Synthesis of Allometrics, Review of Root Biomass and Design of Future Woody Biomass Sampling Strategies. National Carbon Accounting System, Technical Report No. 17, Australian Greenhouse Office, Canberra.
Sokal, R.R. and Rohlf, F.J. (1995) Biometry - The Principles and Practice of Statistics in Biological Research. W.H. Freeman and Company, New York.

State Forests of New South Wales (2000) Annual Report 1999-2000. Pennant Hills NSW.

Stewart, G.A., Gartside, G., Gifford, R.M., Nix, H.A., Rawlins, W.H.M. and Siemon, J.R. (1979) The Potential for Liquid Fuels from Agriculture and Forestry in Australia. CSIRO, Australia.

Ximenes, F.A., Gardner, W.D. and Marchant, J.F. (2005a) Carbon Flow following the Harvest of Blackbutt Trees and their Conversion into Wood Products. Research Paper No. 41, Forest Resources Research, New South Wales Department of Primary Industries, Pennant Hills NSW.

Ximenes, F.A., Gardner, W.D. and Marchant, J.F. (2005b) Total Biomass Measurement and Recovery of Biomass in Commercial Logs in Spotted Gum (Corymbia maculata) Forests in SE NSW. National Carbon Accounting System, Technical Report No. 47, Australian Greenhouse Office, Canberra. 